\title{
Fusion in the vertebral column of the pachyosteomorph arthrodire Dunkleosteus terrelli ('Placodermi')
}

\author{
Zerina Johanson, Kate Trinajstic, Stephen Cumbaa, and Michael J. Ryan
}

\begin{abstract}
Fusion in the vertebral column has evolved multiple times within jawed vertebrates and for these taxa represents normal physiology, with structures such as the sacrum, notarium and pygostyle providing rigidity and support. The synarcual represents the fusion of the anterior part of the vertebral column and occurs in a number of jawed vertebrates, including a variety of placoderms, chondrichthyans and mammals. Placoderms are an entirely fossil group of armoured fishes (Silurian-Devonian), resolved phylogenetically to the base of the jawed vertebrate clade, with vertebrae comprising neural and haemal arches composed of perichondral bone. The placoderm synarcual preserves substantial developmental information from anterior (oldest) to posterior, where new vertebrae are incorporated. This developmental sequence was described recently in the phyllolepid arthrodire Cowralepis mclachlani and ptyctodonts such as Materpiscis attenboroughi, although finer developmental details were not visible. We describe the synarcual in a subadult specimen of the pachyosteomorph arthrodire Dunkleosteus terrelli, preserving 16 paired vertebral elements showing varying degrees of anteroposterior fusion along the vertebral column. Micro-CT scanning of the synarcual provides details of a transitional zone of vertebral modification (involving four of these paired vertebrae, posteriorly), providing unprecedented information on how each vertebra is altered and incorporated into the synarcual. Some of the synarcual elements still retain substantial vertebral identity, showing less fusion overall, thus being more comparable to other arthrodires such as Compagopiscis. By comparison, synarcuals of other taxa, such as the ptyctodont placoderms, along with batoids, holocephalans (Chondrichthyes) and mammals (syncervical) show more complete fusion of vertebral elements.
\end{abstract}

Zerina Johanson. Department of Earth Sciences, Natural History Museum, London, United Kingdom SW75BD.z.johanson@nhm.ac.uk

Kate Trinajstic. Molecular and Life Sciences, Curtin University, Perth, Western Australia, Australia 6845.

K.Trinajstic@curtin.edu.au

Stephen Cumbaa. Department of Paleobiology, Canadian Museum of Nature, Ottawa, Ontario, Canada. scumbaa@mus-nature.ca

Johanson, Zerina, Trinajstic, Kate, Cumbaa, Stephen, and Ryan, Michael J. 2019. Fusion in the vertebral column of the pachyosteomorph arthrodire Dunkleosteus terrelli ('Placodermi'). Palaeontologia Electronica 22.2.20A 1-13. https://doi.org/10.26879/ 872

palaeo-electronica.org/content/2019/2488-dunkleosteus-vertebral-fusion

Copyright: May 2019 Society of Vertebrate Paleontology.

This is an open access article distributed under the terms of the Creative Commons Attribution License, which permits unrestricted use, distribution, and reproduction in any medium, provided the original author and source are credited.

creativecommons.org/licenses/by/4.0/creativecommons.org/licenses/by-nc-sa/4.0/ 
Michael J. Ryan. Department of Vertebrate Paleontology, Cleveland Museum of Natural History, Cleveland, Ohio, USA 44106. michaelpjryan@gmail.com

Keywords: Vertebrae; fusion; placoderm; Dunkleosteus; synarcual

Submission: 28 March 2018. Acceptance: 18 March 2019.

\section{INTRODUCTION}

The Late Devonian (Famennian, 372-358 mya) Cleveland Shale of north central Ohio has historically produced an abundance of early vertebrate fossils, with placoderm and shark specimens dominating the fauna. The bony head and thoracic shield plates of the Cleveland Shale placoderms are well preserved, in contrast to the internal postcranial skeleton, which is rarely preserved. Recently, however, the most complete segment of vertebral column known for the pachyosteomorph arthrodire Dunkleosteus was recovered (CMNH 50322), along with a partially articulated headshield preserving at least 12 dermal plates, both lower jaw elements and a small portion of the trunkshield (Figure 1.1-3). The size of the elements preserved and the presence of deep sensory line canals, indicates that the specimen is a subadult individual of Dunkleosteus terrelli (sensu Carr and Hlavin, 2010), probably less than $3 \mathrm{~m}$ in length.

The vertebrae in this column have been united into a structure known as the synarcual (Figures 1, 2, 3; vertebrae 1-16). The synarcual occurs in several placoderm taxa (Ptyctodontida, Rhenanida, Arthrodira; Jaekel, 1921; Stensiö, 1963; Denison, 1978; Lelièvre and Carr, 2009; Johanson et al., 2010, 2012) and also in chondrichthyans, including skates and rays (Batoidea, Miyake, 1988; Claeson, 2010, 2011; Johanson et al., 2012) and the holocephalans (e.g., elephant shark, Johanson et al., 2015). Anterior fusion also occurs in mammals such as some cetaceans and rodents, as well as reptiles including non-avian dinosaurs and various birds (Van Buren and Evans, 2017), and, therefore, is a common feature throughout jawed vertebrates, in general providing rigidity to the anterior vertebral column.

The placoderm synarcual shows varying degrees of fusion and loss of morphological identity of individual vertebral elements (Johanson et al., 2010, 2012). In arthrodires like Cowralepis mclaughlini and Compagopiscis croucheri (Johanson et al., 2010; Figure 4), for example, vertebral identity is retained in the synarcual, compared to other groups like the ptyctodonts, where separate vertebrae can only be observed posteriorly (e.g.,
Materpiscis, Austroptyctodus; Johanson et al., 2012) and rhenanids (Jaekel, 1921; Lelièvre and Carr, 2009; Johanson et al., 2012; Figure 5). The synarcual in the subadult Dunkleosteus described below includes the more posterior, transitional region in medial or internal view (vertebrae 13-16), which along with micro CT-scanning, provides unprecedented morphological and developmental information for placoderms. The more anterior synarcual in Dunkleosteus, which should extend to the braincase and headshield, is not preserved (Figure 1.2, black dashed line). Dunkleosteus appears more similar to Compagopiscis (Figure 4), showing modification of vertebral elements, but with limited fusion. This may represent an arthrodire-specific pattern when compared to other placoderms.

\section{MATERIALS AND METHODS}

CMNH 50322 consists of a partial Dunkleosteus skeleton that comprises a disassociated, but mostly complete skull with articulated and associated vertebrae. The specimen from the Cleveland Shale Member of the Ohio Shale Formation, collected from a locality along the Rocky River, within the Rocky River Metropark on the west side of Cleveland, in a cliff midway between Little Cedar Point and the Nature Center. The vertebrae are preserved on a block of shale, which includes the left anterior dorsolateral plate (ADL) in anatomical position. There is an $\sim 10 \mathrm{~cm}$ gap between the posterior end of the nuchal plate and the preserved vertebral column, which is offset from the midline of the skull 3-4 cm (Figure 1.2; the ADL and synarcual are more closely positioned here, to conserve space in the figure). Eighteen articulated vertebrae are preserved, each approximately $2.5-3.5 \mathrm{~cm}$ wide $\times 0.7 \mathrm{~cm}$ long. These are numbered $1-18$ from anterior to posterior (Figures 2.1, 3), this refers to preserved vertebrae-vertebra number 1 does not indicate the most anterior vertebra in the column. One additional vertebra was found directly adjacent to the right occipital paraoccipital process of the headshield, as exposed in dorsal view (Figure $6.1)$. The morphology and width $(\sim 2.5 \mathrm{~cm})$ of this single vertebra closely matches the last complete 

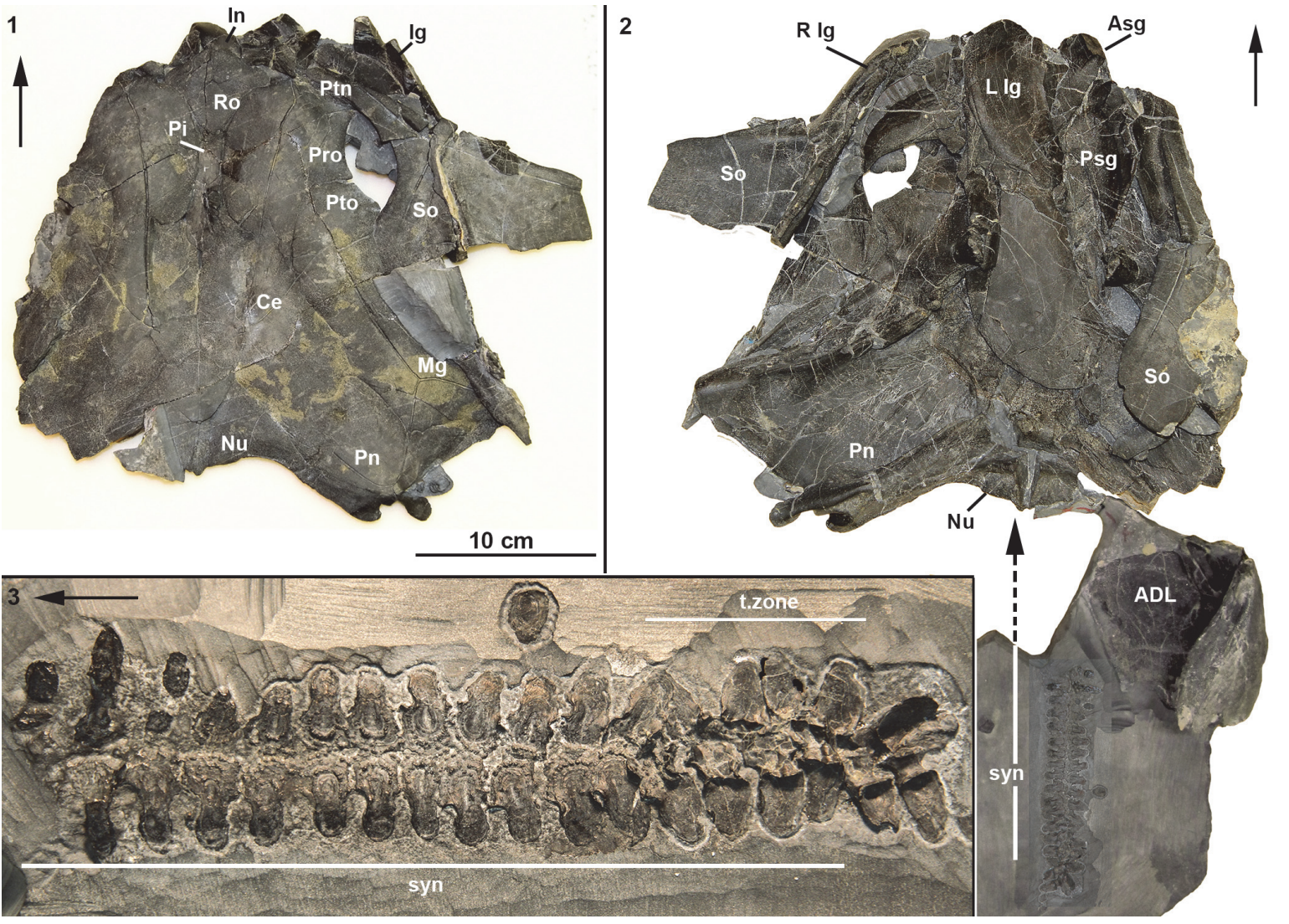

FIGURE 1. Dunkleosteus terrelli CMNH 50322, from Late Devonian (Famennian) Cleveland Shale of northcentral Ohio, macrophotographs. 1, dorsal, external view of headshield; 2, internal view of headshield with associated ADL and anterior vertebral column (preserved synarcual and a small number of unmodified vertebrae preserved); 3 , preserved synarcual oriented anteroposteriorly, and unmodified vertebrae posteriorly. Black arrows indicate anterior. Dashed line in Figure 1.2 indicates anterior continuation of synarcual (not preserved). Abbreviations: ADL, anterodorsal plate of the trunkshield; Asg, anterior supragnathal; Ce, central; lg, ifragnathal; L Ig, left infragnathal; Mg, marginal; Nu, nuchal; Pi, pineal; Pn, paranuchal; Pro, preorbital; Psg, posterior supragnathal; Ptn, postnasal; Pto, postorbital; R Ig, right infragnathal; Ro, rostral; So, suborbital; syn, synarcual; t.zone, transitional zone.

vertebra at the end of the articulated vertebral column (Figures 1.3, 2, 3; numbered 17, 18) and resembles arches preserved in Eastmanosteus calliaspis, a pachyosteomorph arthrodire from Gogo, Western Australia (Dennis-Bryan, 1987; Figure 6.2). As preserved, there are no opposing arch elements, so only half the column is present; given their relationship to the preserved internal surface of the ADL plate (Figure 1.2), these are suggested to represent dorsal neural arch elements.

\section{Fossil Preparation}

$\mathrm{CMNH} 50322$ was initially prepared at the Cleveland Museum of Natural History using hand tools to trim the slabs containing the fossilized bones into manageable sections. The small slabs were then prepared with a SS White Model F industrial air abrasive unit using dolomite abrasive and a Dunmore flexible shaft grinder with carbide silica grinding wheels. The small slab containing the majority of the vertebral elements was then trimmed to allow for CT scanning.

\section{Macrophotography}

Macrophotography of the skull and synarcual was done at the Canadian Museum of Nature with a Canon EOS 7D 35mm digital camera fitted with a Canon zoom EF 24-105mm L IS USM lens and a Canon macro EF100mm 1:2.8 L IS USM lens.

\section{CT-scanning}

The region incorporating paired vertebrae 1018 was CT-scanned at the University of Texas High-Resolution X-ray Computed Tomography Facility, Austin. Scanning was done at $0.02 \mathrm{~mm}$ resolution using a CT scanner that was custombuilt by North Star Imaging, Inc, producing approximately 4250 slices. CT files were rendered using 

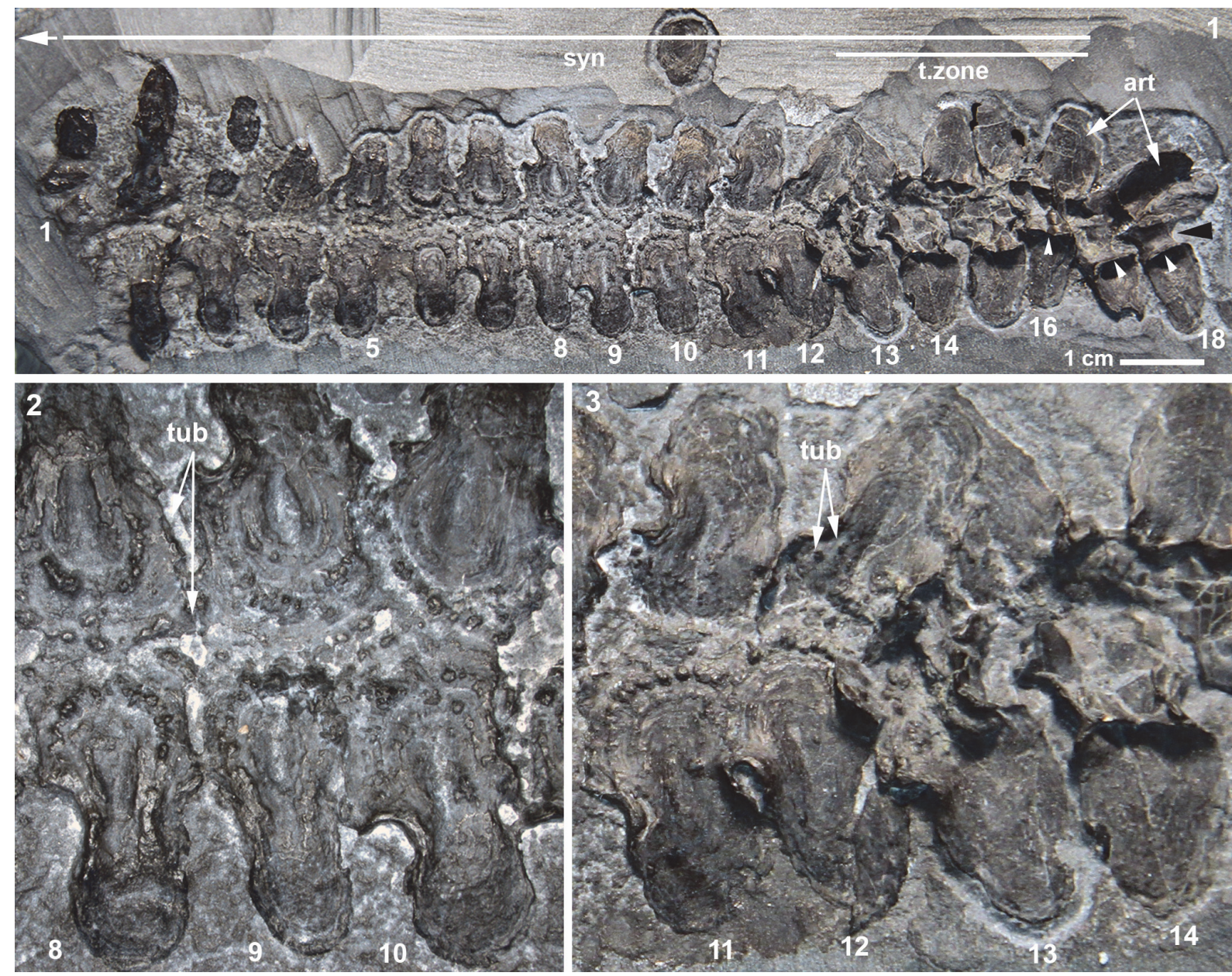

FIGURE 2. Dunkleosteus terrelli CMNH 50322, Late Devonian (Famennian) Cleveland Shale, northcentral Ohio, macrophotographs. 1, entire preserved vertebral column including synarcual. White arrowheads indicate sharp medial border of the scoop-shaped articular surface of the neural arch, black arrowhead indicates 'waisting' between the articular surface and the rest of the arch; 2, closeup of more anterior vertebrae within the synarcual, bone modification (via loss) results in a more 2D element and deposition of woven and perichondral bone between arch bases; $\mathbf{3}$, closeup of more posterior vertebrae, showing loss of medial wall of articular surface (compare vertebrae 14 to 13 , the latter appearing crushed) and transition from more 3D to 2D vertebrae (compare vertebrae 13 and 12). Abbreviations: As in previous figures, also tub, tubercles.

Avizo 9.0 software (https://www.fei.com/software/ avizo3d/).

\section{Institutional Abbreviations}

AMF, Australian Museum, Sydney; AMNH, American Museum of Natural History, New York; MB.f, Museum für Naturkunde, Berlin; CMNH, Cleveland Museum of Natural History, Cleveland; NHMUK, Natural History Museum, London; WAM, Western Australian Museum, Perth.

\section{RESULTS}

\section{Description of the Dunkleosteus Vertebral Column}

Vertebral elements of Dunkleosteus are composed of thin perichondral bone surrounding (unpreserved) cartilage, as in other placoderms (e.g., Dennis and Miles, 1981; Figures 1-4, 6). The placoderm vertebral column includes dorsal and ventral elements (neural, haemal), but centra are generally absent (e.g., Dennis and Miles, 1981; Fleming et al., 2015). In Dunkelosteus, the preserved vertebrae show a morphological transition from the more anterior twelve (1-12) which appear flattened, to the posterior six vertebrae, which are 

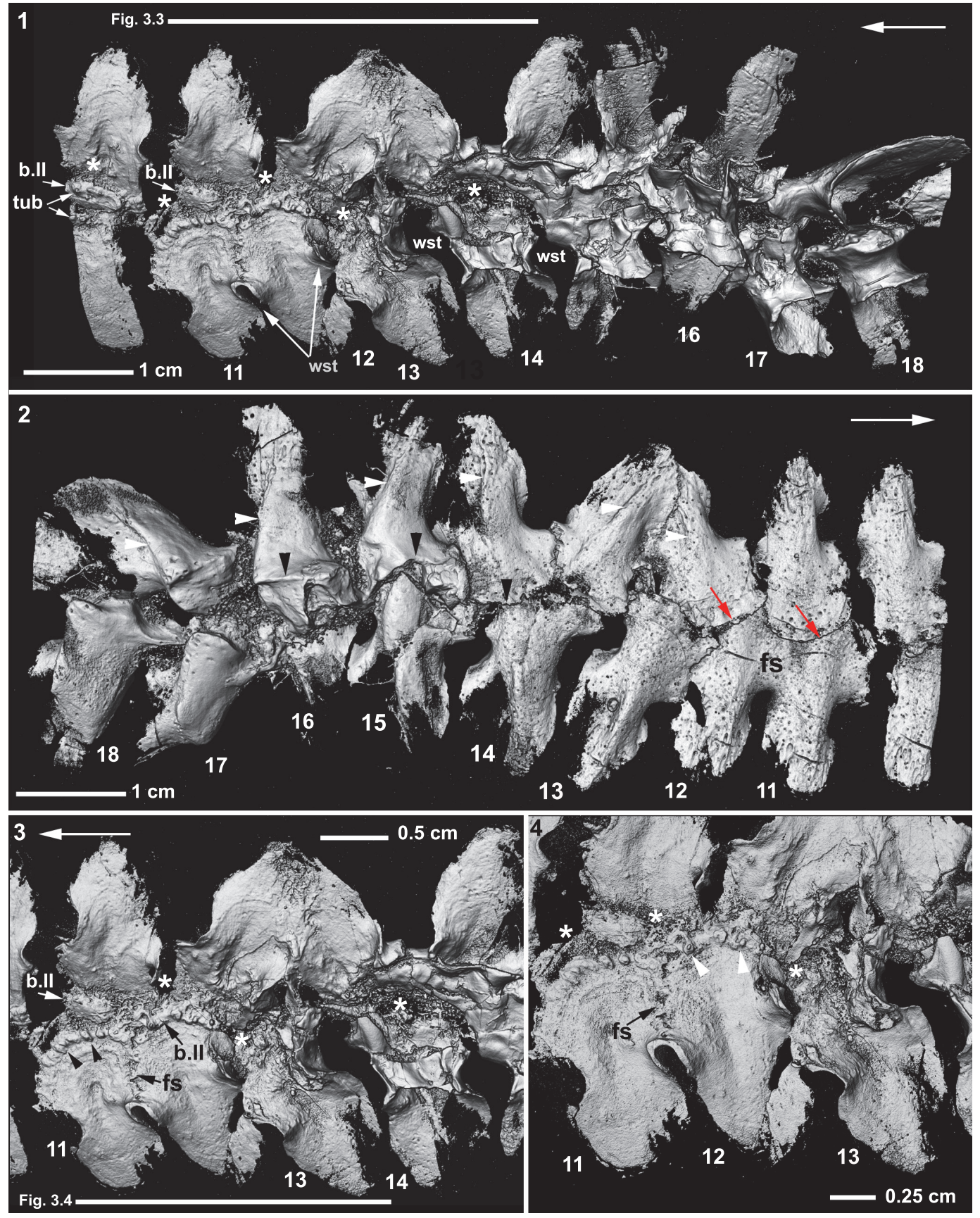

FIGURE 3. 1, Dunkleosteus terrelli CMNH 50322, Late Devonian (Famennian) Cleveland Shale, northcentral Ohio. $3 \mathrm{D}$ volume rendered CT-scans. 1, 2, vertebrae including unmodified outside the synarcual (vertebrae 17, 18) and through transition zone (vertebrae 12-16). Internal view, anterior to left, white asterisk indicates region of woven bone deposition; 2, vertebrae as in Figure 3.1, external view, anterior to right. 3, closeup of vertebrae in transitional zone, and just anterior to this zone (vertebrae 11-14), showing changes in vertebral morphology and deposition of new bone, internal view; 4, closeup of vertebrae 11-13, internal view. White arrows indicate anterior. Abbreviations: As in previous figures, also b.ll, second layer of deposited bone; fs, fusion of vertebrae; peri, deposition of perichondral bone; wst, waisting in vertebrae. Key to asterisks, arrows and arrowheads: Black arrowheads (Figure 3.2) indicate the dorsolateral margin of vertebrae, which is modified in vertebra 14 and those more anteriorly, but unmodified in vertebra 15 and those more posterior. White arrowheads indicate a crest along the lateral vertebral surface, progressively reduced from vertebra 16 to vertebra 13 and more anteriorly. Red arrows (vertebra 11, 12) show unfused dorsomedial margins of the arches, compared to fusion (fs) between the arches anteroposteriorly. Black arrowheads (Figure 3.3; white arrowheads in Figure 3.4) indicate tubercles developing along vertebral margin, via proposed resorption of new bone (b.II). 

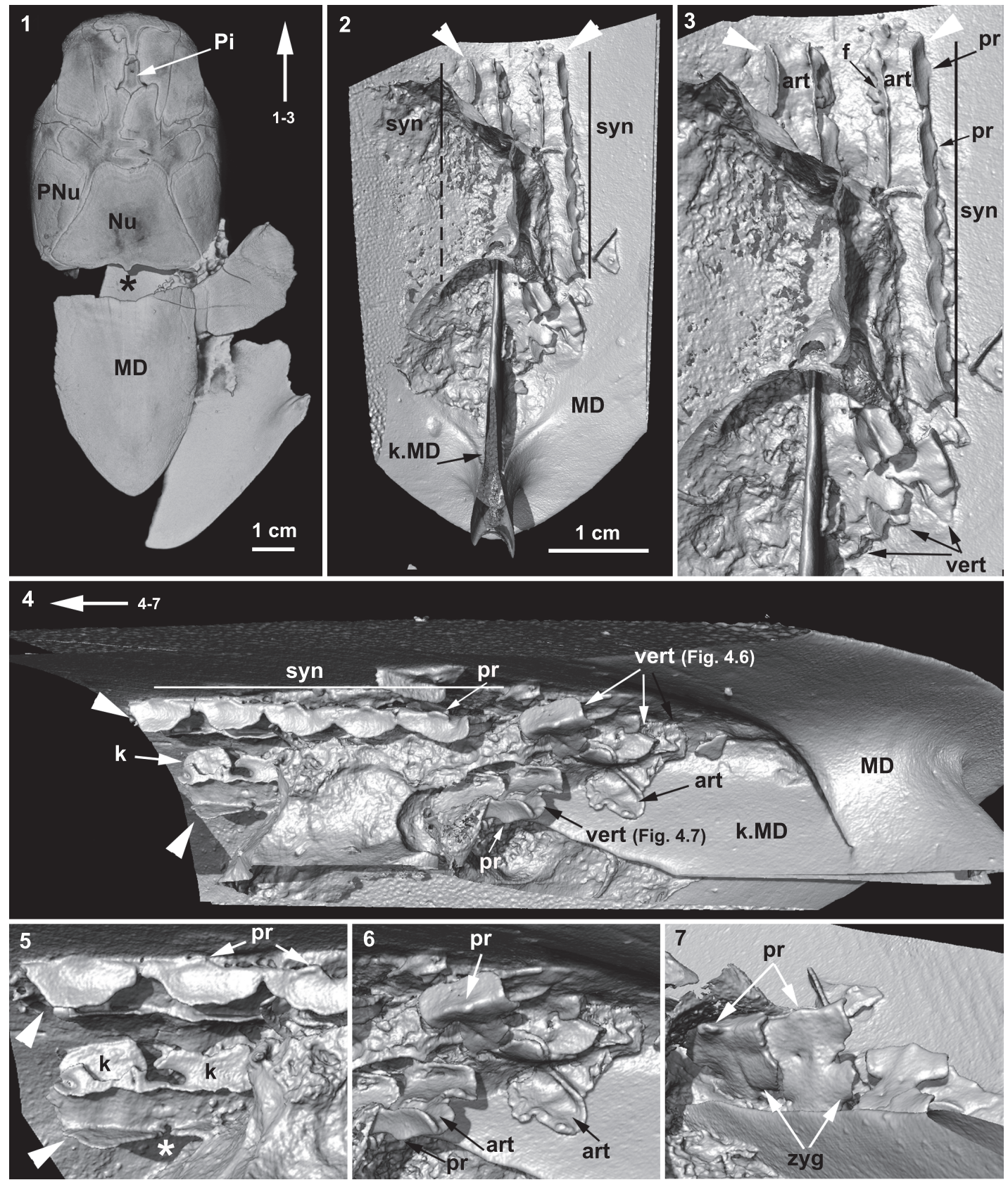

FIGURE 4. Compagopiscis croucheri NHMUK PV P52549, Late Devonian (Frasnian) Gogo Formation, Western Australia. 3D volume rendered CT-scans. 1, Headshield and anterior trunkshield in external view. Black asterisk indicates gap between head and trunkshield. 2, Internal view of median dorsal plate, showing synarcual (syn) comprising 5 modified vertebrae with minimal fusion of individual vertebrae. White arrowheads indicate position of fused vertebrae within the synarcual, paired arch bases and articular surfaces visible in this view. 3, Closeup of synarcual showing rectangular shape of articular surfaces within the synarcual, and dorsolateral processes. 4, lateral view of synarcual, showing more posterior modified and unmodified vertebra, one preserving scoop-shaped articular surface, comparable to other arthrodires such as Dunkelosteus and Eastmanosteus (Figure 5). 5, lateral view of anterior synarcual, showing more modified with weak fusion (white asterisk). Dorsal elements of the synarcual (neural arches) are modified into a keel, as in ptyctodont placoderms (Figure 6). 6, lateral view of vertebrae posterior to the synarcual, showing reduced lateral processes, but modified, rectangular articular surfaces, compared to more posterior vertebrae with scoop-shaped surface. 7, dorsal face of modified vertebrae, showing foramina and zygapophyses. White arrow indicates anterior direction. Abbreviations: as in previous figures, also k, keel on synarcual; k.MD, keel on median plate; MD, median dorsal plate; pr, process on dorsolateral surface of vertebra; vert, vertebrae posterior to synarcual; zyg, zygapophyses. 


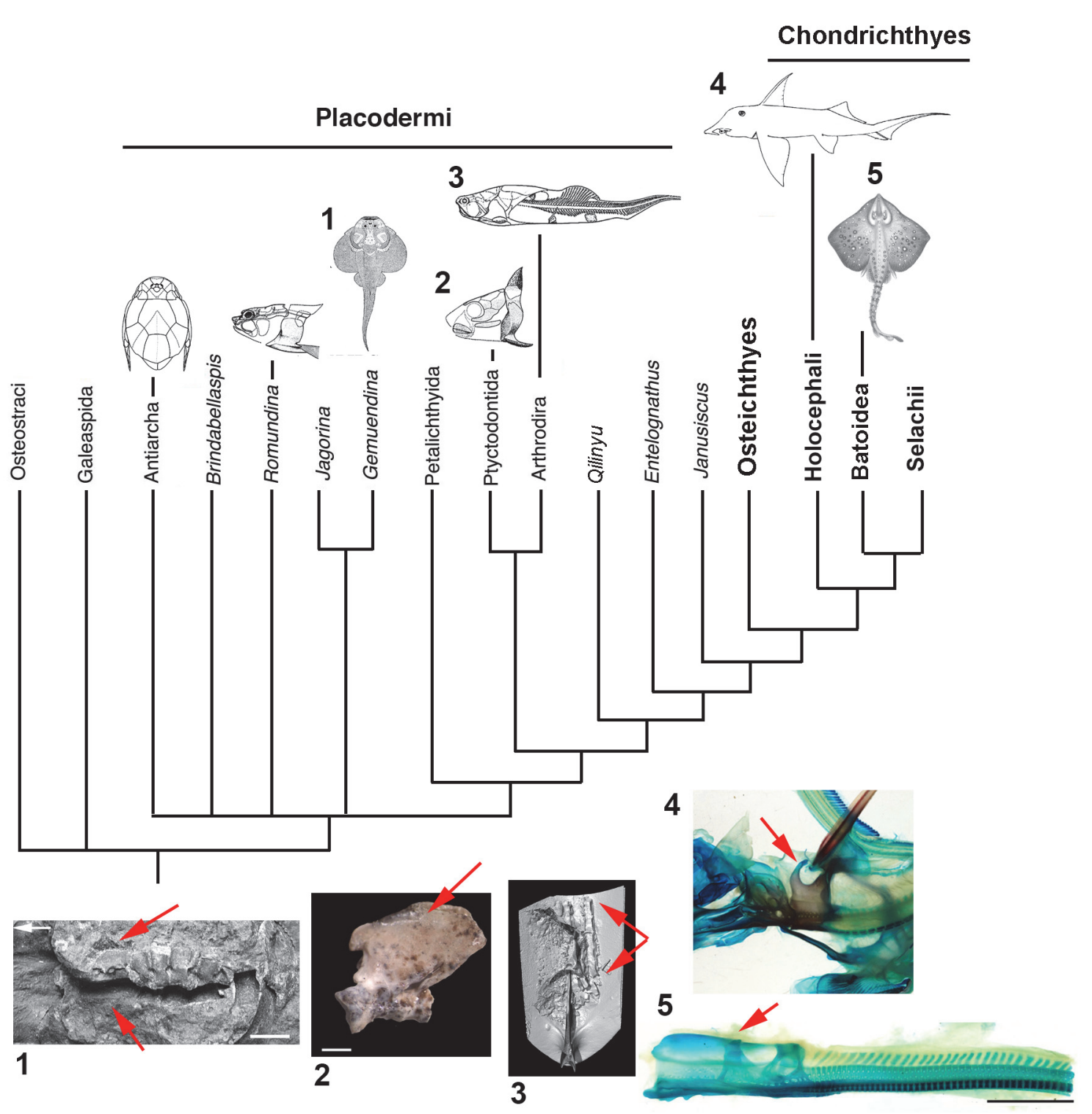

FIGURE 5. Phylogeny of the jawed vertebrates, showing distribution of the synarcual among the paraphyletic Placodermi, and among Chondricthyes, in the Holocephali and Batoidea. Comparable fusion (syncervicals) occur in a range of tetrapods (Van Buren and Evans, 2017), not shown in this cladogram. Cladogram modified from Zhu et al. (2016). Icons in cladogram from Bechard et al. (2014), Johanson and Smith (2003) and University of Washington Freshwater and Marine Image Bank. Images below cladogram (Johanson et al. 2012): 1, Rhenanida synarcual, Jagorina pandora MB.f 510.2; 2, Ptyctodontida synarcual, Austroptyctodus gardineri NHMUK PVP56665; 3, Arthrodira synarcual, Compagopiscis croucheri NHMUK PVP52549; Holocephali synarcual, Chimera monstrosi AMNH 55040; Batoidea synarcual, Dasyastis americana AMNH 30607. Red arrows indicate the position of the synarcual. Scale bars $=1 \mathrm{~cm}$.

$3 \mathrm{D}$ to varying degrees (13-18; Figures 1.3, 2.1, 3.1, 2 ). Some displacement of vertebrae 13-18 has occurred (collapsed against each other), but these, plus the anterior vertebra recovered in association with bony headshield (Figure 6.1), are more separated, individual vertebrae. In particular, this more anterior vertebra, and vertebrae 17,18 , are stout elements dominated by a broadly open, scoopshaped structure, comparable to vertebrae located under the dermal trunkshield in Eastmanosteus (Figure 6.2). Vertebrae 17 and 18 have been displaced so that their midline morphology is more dif- 

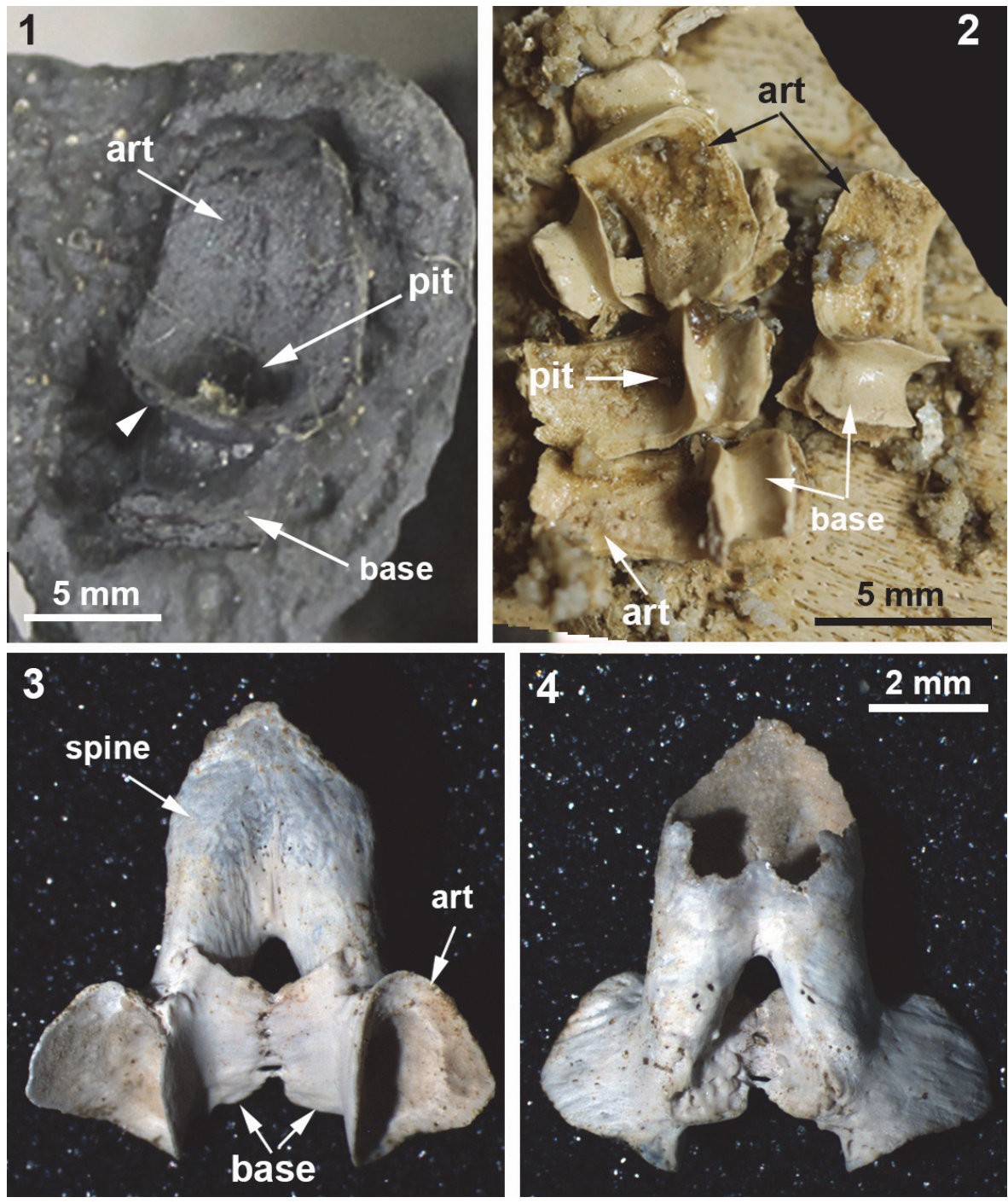

FIGURE 6. 1, Dunkleosteus terrelli CMNH 50322, Late Devonian (Famennian) Cleveland Shale, northcentral Ohio. Isolated vertebral element found near headshield plates, but believed to be from more posterior vertebral column, preserving scoop-shaped articular surface (articulating on notochord) and arch base. White arrowhead indicates sharp margin of articular surface; 2, Eastmanosteus calliaspis, NHMUK PV P54325, Late Devonian (Frasnian) Gogo Formation, Western Australia. Multiple vertebrae with scoop-shaped articular surface and reduced arch base, vertebrae located under bony trunkshield (as in D. terrelli); 3, 4, Eastmanosteus calliaspis, NHMUK PV P57642, Late Devonian (Frasnian) Gogo Formation, Western Australia. More posterior vertebra, posterior to the trunkshield plates, showing fused neural spines. 3, ventral view showing articular surface of arch bases, 4, dorsal view. Abbreviations as in previous figures, also: base, neural arch base, pit, pit within scoop-shaped articular surface.

ficult to interpret, but the anterior vertebra associated with the Dunkleosteus headshield lacks any distortion, showing that the scoop ends in a deep pit and is separated from the rest of the element (base) by a distinct narrowing, or waisting, as in Eastmanosteus vertebrae (Figure 6.1, 2). This curved scoop represents the articular surface resting on the notochord, also seen in Dunkleosteus vertebrae 17 and 18, along with the waisting separating the articular surface from the arch base (Figure 2.1, art, small black arrowhead). Other vertebral elements in Eastmanosteus include a comparable broad scoop, the rest of the arch base, plus an elongate spine; the latter two parts can be fused with their opposite member (Dennis-Bryan, 1987; Figure 6.3-4, spine). These represent more posterior vertebrae in Eastmanosteus, not located under the trunkshield, and suggest that the Dunkleosteus vertebrae preserve the arch base and articular surface, but lack the spines. This includes vertebrae 17 and 18, but also all more anterior preserved vertebrae. Given the relative position of the 
arch articular surface on the specimen and association with the internal surface of the ADL plate, we suggest these elements represent neural arches.

By comparison to vertebrae 17 and 18, most of the anterior vertebrae in the preserved Dunkleosteus column have been modified to some degree. This modification is particularly apparent in a transitional zone, from vertebrae 12-16 (Figures $1.3,2.1$, t.zone). These show a shallower articular surface, with a less well-defined medial margin (Figure 2.1, small white arrowheads), although the lateral margins of the articular area remain well defined. The bases themselves are less well-developed and appear crushed. Externally, a noticeable difference occurs between vertebrae 14 and 15, where the sharp lateral margins have been lost (Figure 3.2, black arrowheads) and the smooth surface of the perichondral bone has also been modified. As well, a sharp crest running from the articular surface to the arch base is reduced from vertebrae 18 to 13, after which the crest is lost (Figure 3.2, white arrowheads).

Internally, the most marked transition occurs between vertebrae 13-14 (Figures 2.1, 2.3, 3.1, 3.3). In vertebra 13, the medial margins of the scoop-shaped articular base have been lost, resulting in a flattened, almost 2D structure. However, the distinct waisting of the vertebra just above the arch base is still visible in vertebra 13 and also vertebrae 11 and 12 (Figure 2.1, wst).

Along with this modification, new bone, identified by the similar open weave morphology seen in embryonic placoderm bone (Long et al., 2009; Johanson and Trinajstic, 2014), was deposited in the transitional zone between the opposing base remnants of vertebrae 10,11 and 12 , and also 13 and 14 (Figure 3.1, 3, 4), where the bases appear out of register. However, given the orderly arrangement of vertebrae anteriorly, this shift may be due to postmortem distortion. It appears that woven bone (i.e., poorly organized, rapid deposition inferred) is first deposited between the bases, with a layer of smooth bone subsequently deposited internally on the woven bone, in irregular patches (b.Il, woven bone indicated by asterisks, Figure $3.1,3,4)$. Associated with this second layer of bone are small rounded tubercles, for example, on vertebra 10 (Figure 3.1, tub). On vertebrae 12, it appears that this second layer of bone is resorbing around the tubercles, such that they become discrete (Figure 3.1, 4, white arrowheads), forming a curvilinear row along the spine edge, best seen in conjunction with vertebra 11 (Figure 3.1, 3, black arrowheads). More anteriorly, the tubercles are organized into rows along the arch margin (Figure 2.1-2). A small number of tubercles are also present internally in vertebrae 13 (Figure 3.3, near the asterisk), although the vertebra itself still retains features of the unmodified vertebrae. Notably, the medial wall of the arch base has been lost in vertebra 13 , while this wall is still present in vertebra 14, where the second layer of bone and tubercles is absent.

In external view, it is clear that although new bone is being deposited, the ventral margins of the neural arch bases remain distinct and presumably unfused, although overlapping occurs (Figure 3.2, red arrows). Bone fusion is occurring, however, along the rostral and caudal margins of the arch bases, best illustrated by vertebrae 11 and 12 (Figure $3.3,4)$. In internal view, bone deposition on these vertebrae occurs along an interfingering margin (fs), without the additional deposition of tubercles, while externally, complete fusion has occurred to form a smooth continuous surface between the vertebrae (Figure 3.2, fs).

Anterior to the transitional zone are the more completely modified vertebrae (Figures 1.3, 2.1). These are flat, two-dimensional structures with some remnant of the waisting present in the more posterior vertebrae. As noted, the anterior vertebrae also show multiple rows of tubercles along the ventral margin of the spine, with up to three curvilinear rows of tubercles on some vertebrae. The second anterior-most vertebra preserved is unusual, in that the arch base has been flattened, as in other modified vertebrae, but the base appears more elongate and thinner, compared to the other anterior vertebrae in the synarcual, but this may be due to damage. The unmodified anterior vertebrae associated with the headshield (Figure 6.1) is considered to come from a more posterior part of the vertebral column (due to the absence of an elongated spine), outside the synarcual, but still located under the trunkshield.

\section{Description of the Compagopiscis Vertebral Column}

The synarcual of Compagopiscis croucheri has been described previously (WAM 94.12.2; Johanson et al., 2012), but CT-scanning of a second specimen (NHMUK PVP52549) provides additional details (Figure 4). The synarcual comprises five fused vertebrae in this specimen and is preserved in association with the median dorsal trunkshield plate, extending to the anterior margin of the plate (Figure 4.2, white arrowheads). The anterior margin of this plate is separated from the head- 
shield and braincase by a gap (Figure 4.1, asterisk) and as in Dunkleosteus, the more anterior part of the synarcual spanning this gap is unpreserved. Fusion of vertebrae within the synarcual occurs between the arch bases and is weak (Figure 4.4, 5, white asterisk), while an expansion of the shortened neural spine into a anteroposteriorly broad keel is present (Figure 4.5, k), reminiscent of the keel in ptyctodont placoderms such as Campbellodus and Austroptyctodus (Johanson et al., 2012; Figure 5). Within the synarcual, the articular surfaces associated with the arch bases and resting on the notochord are rectangular in shape (Figure 4.3, art). A small triangular process is present along the lateral edge of the arch base within the synarcual (Figure 4.3, 5, 7, pr). More posteriorly, separate vertebrae are present (Figure 4.4, 6, vert) with distinct zygapophyses (Figure 4.7, zyg), but these are absent from the fused vertebrae within the synarcual. One of the more posterior vertebra shows a scoop-shaped articular surface, as described for Dunkleosteus and Eastmanosteus (Figure 4.6, art), differing from arch bases in the synarcual, but also within nearby separate vertebral elements (Figure 4.6, art). Based on morphological similarities to the synarcual (e.g., in the articular surface and small lateral processes), these more posterior separate vertebrae could be considered part of a transitional zone within the synarcual, particularly with respect to more posterior vertebrae with a more typical arthrodiran placoderm vertebral morphology.

\section{DISCUSSION}

Despite being known only from fossils, placoderms preserve a substantial amount of developmental data with respect to the formation of the synarcual, including modification of the anterior vertebrae and vertebral fusion. Vertebral elements retain their individuality to varying degrees, indicating that normal somitogenesis and vertebral development occurred, along with cartilage formation/ perichondral bone deposition, prior to the formation of the synarcual (Johanson et al., 2010, 2012: fig. $2 f, g)$. However, because the placoderm synarcual only preserves bone, whether early vertebral development involved separation of an initial continuous cartilage sheath into individual elements, demonstrated most recently for the extant batoid Leucoraja (Criswell et al., 2017), cannot be determined.

The presence of substantial preserved data is particularly true for the arthrodiran placoderm Dunkleosteus terrelli, where a clear antero-poste- rior developmental sequence can be recognized. Modification of vertebral shape is the first step in the process of synarcual formation and involves reduction of the medial margin of the arch base (Figure 2.1), with the scoop-shaped articular surface itself becoming shallower. The medial margin appears crushed compared to more posterior vertebrae (Figure 2.3), as if the bone is becoming thinner; we speculate that this is due to resorption of bone in this region. Externally, the margins of the remnant spine are also becoming modified and less distinct, and the external layers of perichondral bone appear to be lost (again, potentially resorbed, Figure 3.2). In this part of the vertebral sequence, it appears that a more haphazard, woven-type bone is being deposited between the arch bases (vertebra 14, Figure 3.3). Next, the arch base continues to be modified and reduced, with loss of the medial arch wall altogether (vertebra 13, Figure 3.3). This marks the beginning of the transition from a strongly 3D element into a flattened 2D structure. The smooth bone layer is first deposited internally on the scaffold of woven bone associated with vertebra 13, along with a small number of associated tubercles. Anteriorly, the vertebrae are flat, and vertebra 10 in particular shows that the tubercles are embedded within this second, internal bone layer (Figure 3.1). Additional rows of denticles are added internally, with all vertebrae retaining the waisted appearance characterizing unmodified vertebrae (Figure 2.1).

Notably, vertebral modification (remodelling) occurs in two steps: initially, the arch bases and articular surfaces change from strongly $3 D$ to $2 D$ structures, with resorption postulated as the mechanism for this change, but no subsequent deposition of bone. After this, however, the articular surfaces are largely static, while the second stage of modification affects the arch base/remnant spine. This includes continued resorption and initial deposition of woven bone, and then a second layer of bone along the edges of the bases/spines with some fusion and deposition of denticles along the dorsal margin. Thus, the modifications involved in synarcual formation shift from the notochord (arch articular surface) to the more distal (medial) parts of the vertebrae and reflect a shift from resorption to deposition of new bone, including woven, perichondral and a series of tubercles developing from the second layer of bone.

Woven bone forms quickly, with randomly oriented collagen fibres (Figure 3.3-4). It is characteristic of fetal skeletons and has been recognized in placoderm embryos (Long et al., 2009; Johanson 
and Trinajstic, 2014) but in adults can be found where bone is being remodelled, or as part of a pathological condition (Safadi et al., 2009). It need not be associated with a cartilaginous precursor, like regular perichondral bone, but is more of a responsive bone type. Woven bone is normally replaced by stronger lamellar bone, but it is not clear whether this is the case in Dunkleosteus. Additionally, because the second layer of bone is found internal to, and directly on, the woven bone (Figure 3.3-4), it also lacks a cartilaginous precursor and is not perichondral bone. Thus, the new bone deposited in conjunction with synarcual is not perichondral, and differs markedly from the development of the original vertebral column (composed of perichondral bone).

The tubercles are an unusual feature, forming distinct curved rows along what was the neural arch base, incorporated into the synarcual. These tubercles are closely associated with new smooth bone being deposited along the margin of these bases (Figure 3.4, black arrowheads, vertebrae 11), and it appears that discrete tubercles result from the resorption of the surrounding bone (Figure 3.4 , white arrowheads, vertebrae 12). The presence of multiple rows of tubercles would suggest that deposition of this bone is ongoing. However, until this type of internal tubercle is described in a wider range of taxa, their function in Dunkleosteus will remain unclear.

Vertebrae within the synarcual of Dunkleosteus terrelli are modified, but appear to retain substantial morphological identity. Fusion and loss of vertebral identity characterizes the synarcual of the placoderm rhenanids (Lelièvre and Carr, 2009) and ptyctodonts (Johanson et al., 2012), as well as in the synarcual of chondrichthyans (batoids, holocephalans, Johanson et al., 2015; Figure 5, red arrows). In these taxa, vertebrae appear to be largely incorporated into the synarcual. The synarcual of Dunkelosteus sp. from Morocco, previously described by Johanson et al. (2012), also shows a high degree of fusion throughout, although shorter than the synarcual in CMNH 50322 (implying a smaller, younger individual showing less, rather than more fusion). As this synarcual more closely resembles rhenanid and ptyctodont synarcuals, the original assignment to Dunkleosteus should be reconsidered.

By comparison, vertebrae in the synarcual of other arthrodiran placoderms appear to retain more individuality. For example, in Cowralepis (AMF 137328-9), 10 individual arch bases can still be recognized in the synarcual (Johanson et al., 2012: fig. 4c-d), while in the closely related coccosteomorph arthrodire Compagopiscis synarcual (NHM UK PVP52549, WAM 94.12.2), five vertebrae are identifiable due to the weak fusion present only at the base of the vertebral elements (Figure 4.3, 4; Johanson et al., 2012: fig 2b). As well, there appear to be three transitional vertebrae posterior to the synarcual in Compagopiscis, before the more typical morphology occurs (NHMUK PVP52549, WAM 94.12.2; Figure 4.3, 4, vert). In Dunkleosteus terrelli, vertebrae are also modified (transition from a 3D to 2D structure), and bone deposition and fusion appear to only occur in restricted areas along the anteroposterior margins of the vertebral arch base (Figures 2.3, 4.1). The relative lack of vertebral fusion in the arthrodiran synarcual relative to other placoderms may be a specialization of the group. This may be related to the position of this preserved part of the synarcual under the anterior median dorsal trunkshield plate. In batoids, the synarcual supports the expanded pectoral fins (e.g., Claeson 2010, 2011; Johanson et al. 2012), and in holocephalans supports the dorsal fin spine; neither of these functions is applicable to the arthrodiran synarcual. By comparison, the more highly fused ptyctodont and rhenanid synarcuals (Figure 6) confer more rigidity and strength to the anterior vertebral column, potentially linked to supporting head movement during feeding with a crushing dentition in ptyctodonts (e.g., Trinajstic et al., 2012) and support of the expanded pectoral fins in the ray-like rhenanids (Jaekel, 1921).

\section{CONCLUSIONS}

Perhaps surprisingly, some of the best developmental data on vertebral fusion has come from fossil placoderms, over 350 million years old. This comes from both computed tomography and fortuitous preservation of internal structure, as in Dunkleosteus terrelli. Modification (via resorption) and deposition of bone characterizes the $D$. terrelli synarcual, and for the first time, the presence of a precursor disorganized bone has been described, prior to deposition of a second bone layer. Neither of these types of bone is perichondral bone, and so development of the synarcual involves deposition of different and (in terms of the bone associated with the tubercles), potentially novel types of bone. The synarcuals of other placoderm taxa can be examined for these developmental features, to produce a better understanding of vertebral modification at the base of the jawed vertebrate clade. 


\section{ACKNOWLEDGEMENTS}

$\mathrm{CMNH} 50322$ was discovered by M. Reich and collected on May 1, 2008, by the D. Chapman, the late G. Jackson, J. Klunder, M. and D. Reich, and D. Zelinski. The specimen was prepared by long-time volunteer, D. Zelinski. The specimen was CT-scanned by M. Colbert at the University of Texas High-Resolution X-ray CT Facility. ZJ and
KT would like to thank A. McGee and L. Hall (Cleveland Museum of Natural History) for hosting them in the vertebrate paleontology collections (2016). We would like to thank V. Vaŝkaninová for discussion of placoderm synarcuals. KT acknowledges The Australian Research Council Discovery Grant DP140104161.

\section{REFERENCES}

Béchard, I., Arsenault, F., Cloutier, R., and Kerr, J. 2014. The Devonian placoderm fish Bothriolepis canadensis revisited with three-dimensional digital imagery. Palaeontologia Electronica, 17:1-19. https://doi.org/10.26879/417 https://palaeo-electronica.org/content/2014/647-3d-bothriolepis

Carr, R.K. and Hlavin, W.J. 2010. Two new species of Dunkleosteus Lehman, 1956, from the Ohio Shale Formation (USA, Famennian) and the Kettle Point Formation (Canada, Upper Devonian), and a cladistic analysis of the Eubrachythoraci (Placodermi Arthrodira). Zoological Journal of the Linnean Society, 159:195-222. https://doi.org/10.1111/j.10963642.2009.00578.x

Claeson, K. 2010. Trends in Evolutionary Morphology: A Case Study in the Relationships of Angel Sharks and Batoid Fishes. Unpublished Ph.D thesis, The University of Texas at Austin, Austin.

Claeson, K. 2011. The synarcual cartilage of batoids with emphasis on the synarcual of Rajidae. Journal of Morphology, 212:1444-1463. https://doi.org/10.1002/jmor.10996.

Criswell, K.E., Coates, M.I., and Gillis, J.A. 2017. Embryonic development of the axial column in the little skate, Leucoraja erinacea. Journal of Morphology, 278:300-320. https://doi.org/ 10.1002/jmor.20637

Denison, R. 1978. Placodermi. In Schultze, H.-P. (ed.), Handbook of Paleoichthyology, Vol. 2. Gustav Fischer Verlag, Stuttgart and New York.

Dennis, K. and Miles, R.S. 1981. A pachyosteomorph arthrodire from Gogo, Western Australia. Zoological Journal of the Linnean Society, 73:213-258. https://doi.org/10.1111/j.10963642.1981.tb01594.x

Dennis-Bryan, K. 1987. A new species of eastmanosteid arthrodire (Pisces: Placodermi) from Gogo, Western Australia. Zoological Journal of the Linnean Society, 90:1-64. https://doi.org/ 10.1111/j.1096-3642.1987.tb01347.x

Fleming, A·, Kishida, M.G., Kimmel, CB., and Keynes, R.J. 2015. Building the backbone: the development and evolution of vertebral patterning. Development, 142:1733-1744. https:// doi.org/10.1242/dev.118950

Jaekel, O. 1921. Die Stellung der Paläontologie zu einigen Problemen der Biologie und Phylogenie. Palaeontoligscher Zeitschrift, 3:213-239.

Johanson, Z., Boisvert, C., Maksimenko, A., Currie, P., and Trinajstic, K. 2015. Development of the synarcual in the elephant sharks (Holocephali; Chondrichthyes): Implications for vertebral formation and fusion. PLoS ONE, 10(9):e0135138. https://doi.org/10.1371/ journal.pone.0135138

Johanson, Z., Carr, R., and Ritchie, A. 2010. Fusion, gene misexpression and homeotic transformations in vertebral development of the gnathostome stem group (Placodermi). International Journal of Developmental Biology, 54:71-80. https://doi.org/10.1387/ ijdb.072508zj.

Johanson, Z., and Smith, M.M. 2003. Placoderm fishes, pharyngeal denticles, and the vertebrate dentition. Journal of Morphology, 257:289-307. https://doi.org/10.1002/jmor.10124

Johanson, Z., Trinajstic, K., Carr, R., and Ritchie, A. 2012. Evolution and development of the synarcual in early vertebrates. Zoomorphology, 132:95-110. https://doi.org/10.1007/s00435012-0169-9 
Johanson, Z. and Trinajstic, K. 2014. Fossilized ontogenies: the contribution of placoderm ontogeny to our understanding of the evolution of early gnathostomes. Palaeontology, 57:505-516. https://doi.org/10.1111/pala.12093

Lelièvre, H. and Carr, R.K. 2009. The occipital-synarcual complex in Nefudina qalibahensis (Placodermi). Journal of Vertebrate Paleontology, 29:584-588. https://doi.org/ 10.1671/039.029.0233

Long, J.A., Trinajstic, K., and Johanson, Z. 2009. Devonian arthrodire embryos and the origin of internal fertilization in vertebrates. Nature, 457:1124-1127. https://doi.org/10.1038/ nature 07732

Miyake, T. 1988. The Systematics of the Stingray Genus Urotrygon with Comments on the Interrelationships within Urolophidae Chondrichthyes, Myliobatiformes). (Volumes I and II). Unpublished Ph.D. Thesis, Texas A \& M University, College Station.

Safadi, F.F., Barbe, M. R., Abdelmagid, S. M., Rico, M. C., Aswad, R. A., Litvin, J., and Popoff, S. N. 2009. Bone structure, development and bone biology, p. 1-50. In Khurana, J.S. (ed.), Bone Pathology. Springer, New York. https://doi.org/10.1007/978-0-387-89845-2_1

Stensiö, E.A. 1963. Anatomical studies on the arthrodiran head. Part I. Kungliga Svenska vetenskapsakademiens handlingar, 9:1-419.

Trinajstic, K., Long, J.A., Johanson, Z., Young, G.C., and Senden, T. 2012. New morphological information on the ptyctodontid fishes (Placodermi, Ptyctodontida) from Western Australia. Journal of Vertebrate Paleontology, 32:757-780. https://doi.org/10.1080/ 02724634.2012.661379

Van Buren, C.S. and Evans, D.C. 2017. Evolution and function of anterior cervical vertebral fusion in tetrapods. Biological Reviews, 92:608-626. https://doi.org/10.1111/brv.12245

Zhu, M., Ahlberg, P.E., Pan, Z., Zhu, Y., Qiao, T., Zhao, W., Jia, L., and Lu, J. 2016. A Silurian maxillate placoderm illuminates jaw evolution. Science, 354:334-336. https://doi.org/10.1126/ science.aah3764 